Research Article

\title{
Drainage in a Screw Press and Utilization of the Recovered Fibres after Thermo-Hydrolytic Disintegration of Waste Fibreboards
}

\author{
Fahriye Yağmur Bütün Buschalsky*, Carsten Mai
}

Department of Wood Biology and Wood Products, Georg-August-Universität, Büsgenweg 4, 37077 Göttingen, Germany; E-Mails: ybuetue@gwdg.de; cmai@gwdg.de

* Correspondence: Fahriye Yağmur Bütün Buschalsky; E-Mail: ybuetue@gwdg.de

Academic Editor: Jorge de Brito

Special Issue: Wastes, Residues and Byproducts for the Production of Construction Materials

Recent Progress in Materials

2021, volume 3, issue 3

doi:10.21926/rpm.2103029
Received: March 15, 2021

Accepted: July 07, 2021

Published: July 22, 2021

\begin{abstract}
A thermo-hydrolytic disintegration process qualifies as a promising option for recycling the waste MDF and preserving the fibrous morphology of the recovered lignocellulosic fibre material. This study aims to include a drainage process between the thermo-hydrolytic disintegration and the further utilization of the recovered fibres (RF) obtained using a screw press for removing the disintegration water (DW). In this context, the chemical properties of the $\mathrm{RF}(\mathrm{pH}$, nitrogen content, formaldehyde emissions) and the $\mathrm{DW}(\mathrm{pH}$, formaldehyde, reducing sugars and equivalents and nitrogen contents) were analyzed. Moreover, the RF material was utilized to produce recycled MDF panels, solely containing the RF $(100 \%)$ and hence supplanting $50 \%$ of the virgin fibres (VF). The recycled MDF portrayed significant reductions in the internal bond strength (IB), and flexural properties (MOR, MOE): in the case of MDF made from $100 \%$ recycled fibres, about half the strength was reduced, and in the case of MDF made from $50 \%$ recycled fibres, the strength was reduced by $20-25 \%$. The Thickness swelling (TS) of the recycled MDF panels was similar, while the water uptake (WA) was higher than that of the original MDF. The recycled MDF panels also exhibited a higher content of formaldehyde and emission. The findings recommend the application of a screw press process for prompter drainage of the RF and to utilize the RF obtained in combination with the VF to
\end{abstract}

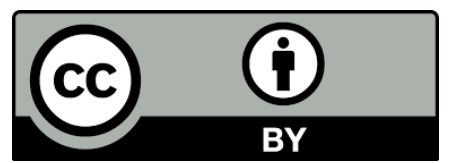

(C) 2021 by the author. This is an open access article distributed under the conditions of the Creative Commons by Attribution License, which permits unrestricted use, distribution, and reproduction in any medium or format, provided the original work is correctly cited. 
achieve adequate mechanical properties rather than using the RF separately for the manufacturing of the recycled MDF panels.

\section{Keywords}

Fibreboards; MDF; wood-based panels; waste; thermo-hydrolytic disintegration; screw press; mechanical properties; physical properties; formaldehyde release

\section{Introduction}

Fibreboards are defined as a dry-formed panel product manufactured from ca. $80-90 \%$ of fine lignocellulosic fibres are obtained from the thermo-mechanical pulping (TMP) from a refiner combined with a synthetic adhesive (generally urea-formaldehyde, UF resin). The global production of medium-density fibreboards (MDF) along with high-density fibreboards (HDF) reached a total of 98.6 million $\mathrm{m} 3$ in 2018 [1]. On completion of their service life, these panels turn into waste, and a majority are deposited in landfills or are burned. In Europe, waste wood materials consisting of more than 5\% of organic materials have been prohibited from landfilling since 2005 [2]. Recycling of the MDF wastes presents an opportunity for extending the application of wood resources, reduction in the consumption of new resources, energy, landfilling as well as the expenses avoided through purchase/disposal fees, and helps in the creation of "green" jobs [3]. The thermo-hydrolytic disintegration process would be a promising option to preserve the fibrous morphology of the recovered lignocellulosic fibre material during the release of the fibres from the thermosetting resin matrix. Thermo-hydrolytic disintegration processes involve the application of liquid water, steam, heat and occasionally pressure for cleaving the existing adhesive bonds in waste MDF [2]. Toward the end of the disintegration process, recovered fibres (RF) and a resin-water mixture, termed disintegration water (DW), are obtained. The implementation of an appropriate de-watering process for separating the RF from the DW is an important aspect for reducing the drying time of the RF.

The effects of using RF on the properties of the newly produced MDF after repeated thermohydrolytic disintegration processes have been investigated [4]. This study aims to implement a drainage process between the previously researched thermo-hydrolytic disintegration process and the further utilization of the obtained RF using a screw press for removing the DW. In this context, the analysis of the chemical and morphological properties of the RF and the chemical properties of the DW was made. Moreover, the RF material is utilized for producing recycled MDF panels solely containing the RF (100\%) and supplanting $50 \%$ of these by virgin fibres. The paper also explains the physicomechanical as well as chemical (such as formaldehyde release) properties of these MDF panels.

\section{Materials and Methods}

\subsection{Materials}

Three types of uncoated industrial fibreboards (medium-density fibreboard-MDF and highdensity fibreboard-HDF) having different densities, thicknesses, as well as binder types and amounts, 
were used for the thermo-hydrolytic disintegration process (Table 1 and Figure 1). Moreover, the nitrogen content (NC) of the panels was determined using the Kjeldahl method as described previously [5]. The UF content of the MDF panels was calculated keeping in mind that the UF resin contained roughly $30 \%$ nitrogen, neglecting the very low NC of the fibres $(<0.1 \%)$ used for producing the panels [4] (Table 1). However, due to the complexity in formulation, the UF content for Board1 could not be calculated from the nitrogen content alone.

Table 1 Properties of the uncoated industrial fibreboards.

\begin{tabular}{cllll}
\hline Fibreboard properties & Board-1 & Board-2 & Board-3 \\
\hline Fibreboard type & MDF & MDF & HDF \\
Density $\left(\mathrm{kg} \mathrm{m}^{-3}\right)$ & 792 & 739 & 862 \\
Thickness (mm) & 6.0 & 19.0 & 6.6 \\
Binder type & Urea formaldehyde (UF) amount (\%) & 5.5 & 9.9 & 14.7 \\
& Melamine urea formaldehyde amount (\%) & 10.5 & 0 & 0 \\
& Analyzed nitrogen content (\%) & 6.0 & 3.6 & 5.0 \\
Calculated UF content (\%) & n.c. & 11.5 & 16.0 \\
\hline
\end{tabular}

n.c. = "not calculated".

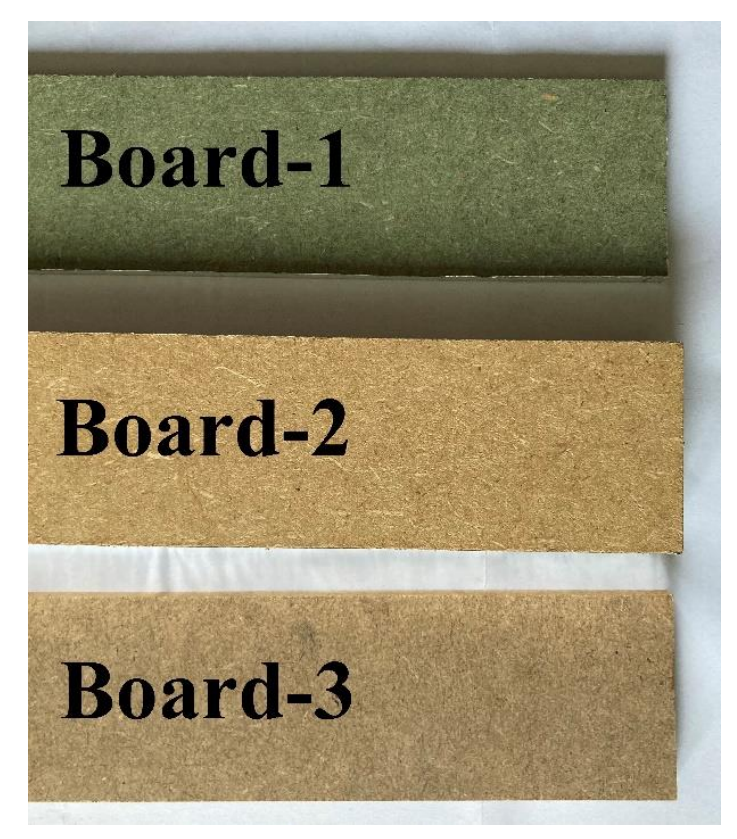

Figure 1 Uncoated industrial fibreboards used for the thermo-hydrolytic disintegration process.

\subsection{Thermo-Hydrolytic Disintegration of Waste Fibreboards}

Firstly, each fibreboard type was cut into pieces having dimensions of $25 \times 25 \mathrm{~mm}^{2}$ in crosssection by using a circular saw. The thermo-hydrolytic disintegration process was carried out separately for each type of fibreboard. Hence, for every disintegration, $9 \mathrm{~kg}$ of these fibreboard pieces were immersed in 30 liters of water at $95{ }^{\circ} \mathrm{C}$ in the autoclave Zirbus Z3 (Zirbus Technology $\mathrm{GmbH}$, Bad Grund, Germany) for $30 \mathrm{~min}$ (Figure 2a). After every disintegration process, the 
recovered fibres, along with the disintegration water, were stored in barrels made of high-density polyethene and was sent to Maschinenfabrik Reinartz GmbH \& Co. KG (Neuss, Germany).

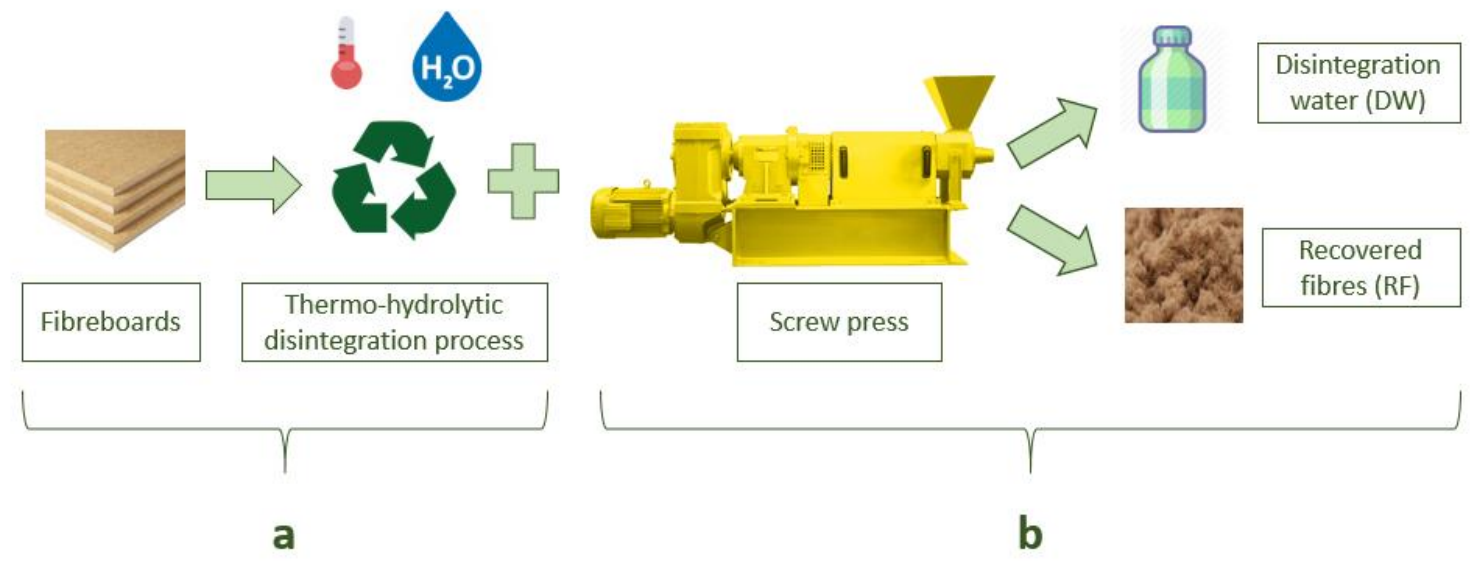

Figure 2 Schematic illustration of a) Thermo-hydrolytic disintegration of waste fibreboards, b) Drainage of recovered fibres using a screw press.

\subsection{Drainage of Recovered Fibres Using a Screw Press}

The excess water (disintegration water -DW) was removed using a screw press developed by Maschinenfabrik Reinartz GmbH \& Co. KG (Neuss, Germany). Thus, the RF and DW were obtained separately (shown in Table 2 and Figure 2b). To determine the chemical and morphological properties, the RF was conditioned in a climate chamber at $20^{\circ} \mathrm{C}$ with $65 \%$ relative humidity.

Table 2 Labeling system of the recovered fibres (RF) obtained and disintegration water (DW) samples after the disintegration processes.

\begin{tabular}{ccc}
\hline Disintegrated fibreboard & Obtained recovered fibre & Obtained disintegration water \\
\hline Board-1 & RF1 & DW1 \\
Board-2 & RF2 & DW2 \\
Board-3 & RF3 & DW3 \\
\hline
\end{tabular}

\subsection{Determination of the Chemical Properties of the Recovered Fibres}

The $\mathrm{pH}$ value was measured after the extraction of fibres from cold water ( 4 specimens per fibre type); $2 \mathrm{~g}$ of sample material was placed in a $100 \mathrm{~mL}$ Erlenmeyer flask, and $60 \mathrm{~mL}$ of distilled water was added. Afterwards, the Erlenmeyer flask was placed on a shaker present at room temperature, and the measurements were made after periods of $50 \mathrm{~min}, 6 \mathrm{~h}$, and $24 \mathrm{~h}$, respectively, with the help of pH electrode InoLab Level 2 (WTW GmbH, Weilheim, Germany). Due to minor differences, only the average $\mathrm{pH}$ value was reported for each type of fibre. The Nitrogen content was determined using the Kjeldahl method to assess the remaining UF resin content on the RF2 and RF3 after thermo-hydrolytic disintegration (4 specimens per fibre type), as previously described in [5]. Through the calculation of the remaining resin content on the RF, it was assumed that the UF resin contains roughly $30 \%$ nitrogen. The proportion of initial contents of the binder, which had remained 
on the RF, was calculated by relating the $\mathrm{NC}$ of the RF to the $\mathrm{NC}$ of the respective MDF. Formaldehyde emissions from the fibre mass were determined based on the basic principle of the standard EN 717 3, which used approximately $2 \mathrm{~g}$ of the fibre material in a bleached tea bag (4 specimens per fibre type), and the values were recorded after $3 \mathrm{~h}$ of emission [6]. All the results were compared to industrially produced thermo-mechanical pulp (TMP) fibres (virgin fibres-VF) as a reference.

\subsection{Chemical Analysis of the DW}

Analysis was made on the disintegration water samples for obtaining the $\mathrm{pH}$ value, including the formaldehyde content based on the acetylacetone method (EN 120 [7]) and nitrogen content based on the Kjeldahl method (4 specimens per DW sample) as described previously in [5]. The amount of reducing sugar equivalents in the DW was assessed based on the 3.5 dinitrosalicylic acids (DNSA) method (4 specimens per DW sample) [8].

\subsection{Production of the Recycled MDF Panels Using RF2}

Recovered fibres obtained after the disintegration of Board-2 were selected for manufacturing recycled MDF panels due to their compatibility with the thickness of the original board and resin content with the susceptible comparison of the previous research made by the authors. Recycled MDF panels (1 replica per panel) were manufactured using the RF2 obtained by the disintegration of the Board-2. Further disintegration of the RF2 was made in the hammer-mill VS1 N (Electra SAS, Poudenas, France) using a mesh size of $2.0 \mathrm{~mm}$. Two different types of MDF panels containing 100\% and 50\% hammer-milled RF2 were produced and labelled as B100 and B50, respectively (Figure 3). The other $50 \%$ of the formulation of the B50 was made up of industrially produced thermomechanical pulp (TMP) fibres (virgin fibres-VF). These were blended with the RF2 after hammermilling as performed previously. The MDF panels were produced with 10\% UF resin (Kaurit 350, BASF, Ludwigshafen, Germany) based on dry fibre mass and $2 \%$ ammonium sulfate $\left(\left(\mathrm{NH}_{4}\right)_{2} \mathrm{SO}_{4}\right)$ as a hardener based on the solid content of the resin. The resin and the hardener were pneumatically applied onto the fibres within a rotary drum using a spraying nozzle. The resinated fibre material was further hot-pressed $\left(190{ }^{\circ} \mathrm{C}, 5 \mathrm{~N} \mathrm{~mm}^{-2}\right)$ for $15 \mathrm{~s} \mathrm{~mm}^{-1}$ to attain a target density of $700 \mathrm{~kg} \mathrm{~m}^{-3}$ using metal bar stops to reach a panel thickness of $16 \mathrm{~mm}$. 


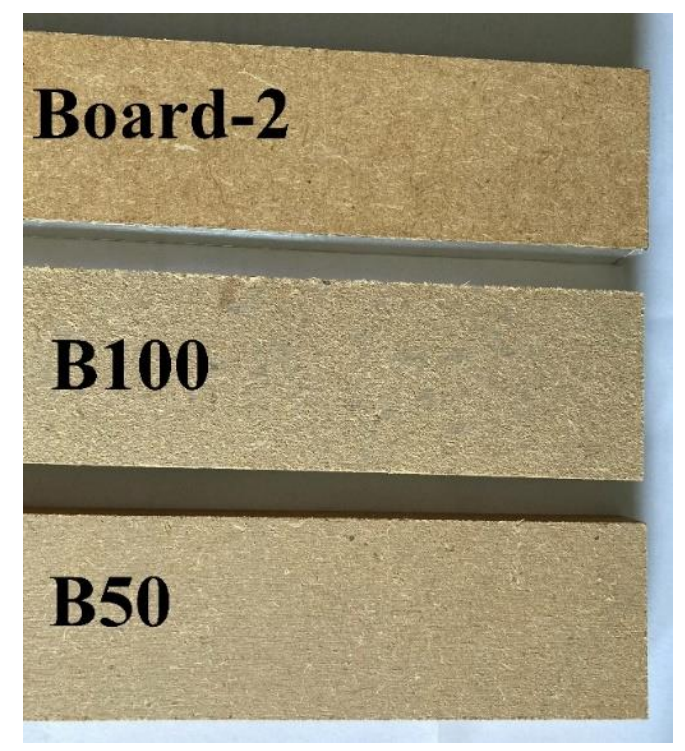

Figure 3 Uncoated industrial Board-2 fibreboard and recycled MDF panels (B100 a B50) produced using recovered fibres obtained by the disintegration of Board-2 (RF2).

\subsection{Determination of the Physico-Mechanical and Chemical Properties of the MDF Panels}

All the MDF panels and the respective cut specimens were conditioned at $20{ }^{\circ} \mathrm{C}$ having $65 \%$ relative humidity until a constant mass was reached. The density of each individually cut MDF specimen was determined as per EN 323, and the overall density of the panel was calculated as the average of these samples [9]. In addition, the following properties were assessed: the moisture content (MC) according to EN 322 (36 specimens, 12 per panel), internal bond strength (IB) according to EN 319, the thickness swelling (TS) and water uptake (WU) after immersion in water for $24 \mathrm{~h}$ according to EN 317 while applying the sample dimensions of $50 \times 50 \times 16 \mathrm{~mm}^{3}$ (4 specimens per Board-2 and three specimens per recycled panel), the flexural strength (MOR) and modulus of elasticity (MOE) according to EN 310 while applying the sample dimension of $370 \times 50 \times 16 \mathrm{~mm}^{3}$ (two specimens per Board-2 and three specimens per recycled panel) [10-13]. The Formaldehyde content was determined as per the EN 120, perforator method) (1 specimen per panel), while the formaldehyde emission of the boards was analyzed according to EN 717-2 (gas analyzer method [14]) (two specimens of Board-2 and one specimen per recycled panel) and EN 717-3 [6], flask method) with two specimens for every panel for $3 \mathrm{~h}$ and $24 \mathrm{~h}$ [7]. The NC of the panels was determined using the Kjeldahl method (three specimens per Board-2 and two specimens for every recycled panel) as described previously in [5]. The binder content of the produced original and the recycled UF bonded MDF panels were calculated considering the UF resins contained roughly $30 \%$ nitrogen when the very low NC of the virgin fibres were ignored $(\leq 0.1 \%$ ) (Table 1 and Table 3). All the aforementioned properties were also analyzed for the Board-2 before being disintegrated using the thermo-hydrolytic process. 
Table 3 Physico-mechanical and chemical properties of industrially produced B2, 100\% RF containing recycled B100, 50\% recovered fibres (RF) and $50 \%$ virgin fibres containing recycled B50 MDF panels; $\mathrm{N}=$ specimen amount per panel, mean values (MV) \pm standard deviation (SD).

\begin{tabular}{|c|c|c|c|c|c|c|c|c|c|}
\hline \multirow{2}{*}{$\frac{\text { MDF properties }}{\text { MDF type and used fibre type }}$} & \multicolumn{3}{|c|}{ Board-2 } & \multicolumn{3}{|c|}{$\mathrm{B} 100$} & \multicolumn{3}{|l|}{ B50 } \\
\hline & \multicolumn{3}{|c|}{$\begin{array}{l}\text { Industrially produced, } 100 \% \text { virgin } \\
\text { fibres }\end{array}$} & \multicolumn{3}{|c|}{ Recycled, $100 \%$ RF2 } & \multicolumn{3}{|c|}{ Recycled, 50\% RF2 and 50\% VF } \\
\hline & $\mathrm{N}$ & MV & SD & $\mathrm{N}$ & MV & SD & $\mathrm{N}$ & MV & SD \\
\hline Number or replica panel & 8 & $\mathrm{n} / \mathrm{a}$ & $\mathrm{n} / \mathrm{a}$ & 1 & $\mathrm{n} / \mathrm{a}$ & $\mathrm{n} / \mathrm{a}$ & 1 & $\mathrm{n} / \mathrm{a}$ & $\mathrm{n} / \mathrm{a}$ \\
\hline Density $\left(\mathrm{kg} \mathrm{m}^{-3}\right)$ & 21 & 739.0 & 5.6 & 21 & 715.0 & 25.9 & 21 & 681.5 & 30.6 \\
\hline Thickness (mm) & $\mathrm{n} / \mathrm{a}$ & 19.0 & n.c & $\mathrm{n} / \mathrm{a}$ & 16.0 & n.c & $\mathrm{n} / \mathrm{a}$ & 16.0 & n.c. \\
\hline Moisture content (MC) (\%) & 12 & 7.8 & $\leq 0.1$ & 12 & 7.2 & $\leq 0.1$ & 12 & 6.8 & $\leq 0.1$ \\
\hline $\begin{array}{l}\text { Internal bond strength (IB) ( } \mathrm{N} \mathrm{mm}^{-} \\
\left.{ }^{2}\right)\end{array}$ & 4 & 0.3 & $\leq 0.1$ & 3 & 0.1 & $\leq 0.1$ & 3 & 0.2 & $\leq 0.1$ \\
\hline Flexural strength $\left(\mathrm{N} \mathrm{mm}^{-2}\right)$ & 2 & 30.6 & 1.9 & 3 & 12.3 & 2.1 & 3 & 24.0 & 1.0 \\
\hline $\begin{array}{l}\text { Modulus of elasticity (MOE) ( } \mathrm{N} \mathrm{mm}^{-} \\
\left.{ }^{2}\right)\end{array}$ & 2 & 3735.3 & 50.4 & 3 & 1610.0 & 306.2 & 3 & 2566.0 & 254.8 \\
\hline Water uptake (\%) & 4 & 19.0 & 1.1 & 3 & 35.9 & 1.0 & 3 & 40.7 & 1.4 \\
\hline Thickness swelling (\%) & 4 & 10.0 & 1.6 & 3 & 10.1 & 0.1 & 3 & 8.9 & 0.2 \\
\hline $\begin{array}{l}\text { Formaldehyde content - Perforator } \\
\text { method (mg } 100 \mathrm{~g}^{-1} \text { o.d. board) }\end{array}$ & 1 & 2.0 & $\mathrm{n} / \mathrm{a}$ & 1 & 11.0 & $\mathrm{n} / \mathrm{a}$ & 1 & 13.7 & $\mathrm{n} / \mathrm{a}$ \\
\hline $\begin{array}{l}\text { Formaldehyde emission - Gas } \\
\text { analyser method }\left(\mathrm{mg} \mathrm{m}^{-2} \mathrm{~h}^{-1}\right)\end{array}$ & 2 & 2.5 & $\leq 0.1$ & 1 & 10.1 & $\mathrm{n} / \mathrm{a}$ & 1 & 10.5 & $\mathrm{n} / \mathrm{a}$ \\
\hline $\begin{array}{l}\text { Formaldehyde emission - Flask } \\
\text { method (mg kg-1 o.d. board) } 3 \mathrm{~h}\end{array}$ & 2 & 2.5 & $\leq 0.1$ & 2 & 7.3 & 0.8 & 2 & 7.5 & $\leq 0.1$ \\
\hline $\begin{array}{l}\text { Formaldehyde emission - Flask } \\
\text { method (mg kg-1 o.d. board) } 24 \mathrm{~h}\end{array}$ & $\mathrm{n} / \mathrm{a}$ & n.a. & n.c & 2 & 104.7 & 5.7 & 2 & 116.1 & 6.7 \\
\hline Nitrogen content (\%) & 3 & 3.6 & $\leq 0.1$ & 2 & 4.9 & $\leq 0.1$ & 2 & 3.8 & $\leq 0.1$ \\
\hline Calculated UF content (\%) & $\mathrm{n} / \mathrm{a}$ & 11.5 & n.c & $\mathrm{n} / \mathrm{a}$ & 15.7 & n.c & $\mathrm{n} / \mathrm{a}$ & 12.2 & n.c \\
\hline
\end{tabular}

n/a = "not applicable", n. c. =" not calculated", n. a. = "not analyzed" 


\section{Results}

\subsection{Chemical Properties of the Recovered Fibres}

The moisture content of the recovered fibres (RF) was as low as $20 \%$, indicating the effectiveness of the drainage process. As the moisture content was well below the fibre saturation point of coniferous wood such as spruce, it could be assumed that the degradation of the cell wall occurs or that the fibres were lost during processing. As bound water is held by intermolecular attraction within cell walls, this water cannot easily be removed unless the cell walls are broken [15]. The $\mathrm{pH}$ value of virgin fibres (VF) amounted to 4.0, while those of the recycling fibres (RF) ranged between 5.5 and 6.3 (Table 4). The higher pH of the RF may be attributed to the UF and the MUF resin itself, including the alkaline ammonia formed as a result of degradation from the resins during disintegration. Under acidic conditions in an aqueous environment, ammonia forms ammonium [16, 17], which results in the $\mathrm{pH}$ increment of the RF samples. 
Table 4 Chemical properties of the virgin fibres (VF) and recovered fibres (RF), the mean values (MV) \pm standard deviation (SD).

\begin{tabular}{|c|c|c|c|c|c|c|c|c|c|c|}
\hline \multirow[t]{3}{*}{ Chemical properties } & \multicolumn{4}{|c|}{ Virgin fibres (VF) } & \multirow{3}{*}{$\begin{array}{l}\text { RF1 } \\
\text { MV }\end{array}$} & \multicolumn{3}{|c|}{ RF2 } & \multicolumn{2}{|l|}{ RF3 } \\
\hline & \multicolumn{2}{|c|}{ Non-milled } & \multicolumn{2}{|c|}{ Hammer-milled } & & & & & & \\
\hline & MV & SD & MV & SD & & SD & MV & SD & MV & SD \\
\hline $\begin{array}{l}\text { Moisture content after drainage } \\
\text { (\%) }\end{array}$ & $\mathrm{n} / \mathrm{a}$ & $\mathrm{n} / \mathrm{a}$ & n/a. & $\mathrm{n} / \mathrm{a}$ & 20.1 & n.c. & 22.0 & n.c. & 20.7 & n.c. \\
\hline $\begin{array}{l}\text { Moisture content after } \\
\text { conditioning (\%) }\end{array}$ & 7.1 & $\leq 0.1$ & 8.9 & $\leq 0.1$ & 17.9 & 2.1 & 11.0 & 0.3 & 11.4 & 0.8 \\
\hline $\mathrm{pH}(50 \mathrm{~min}, 6$ and $24 \mathrm{~h})$ & 4.2 & $\leq 0.1$ & 4.2 & $\leq 0.1$ & 6.3 & 0.1 & 5.5 & 0.1 & 6.2 & 0.1 \\
\hline Nitrogen content (\%) & 0.1 & $\leq 0.1$ & 0.1 & $\leq 0.1$ & 2.8 & $\leq 0.1$ & 1.7 & $\leq 0.1$ & 3.3 & $\leq 0.1$ \\
\hline Calculated UF content (\%) & n.c & n.c & n.c & n.c & n.c. & n.c. & 5.4 & n.c. & 10.6 & n.c. \\
\hline $\begin{array}{l}\text { Amount of initial binder content } \\
\text { remained on the fibres (\%) }\end{array}$ & $\mathrm{n} / \mathrm{a}$ & n.c & $\mathrm{n} / \mathrm{a}$ & n.c. & 46.6 & n.c. & 47.0 & n.c & 66.2 & n.c. \\
\hline $\begin{array}{l}\text { Formaldehyde emission-Flask } \\
\text { method ( } \mathrm{mg} / \mathrm{kg} \text { o.d. fibre) }(3 \mathrm{~h})\end{array}$ & 5.6 & 0.2 & 9.1 & 0.07 & 57.2 & 0.9 & 29.6 & 5.8 & 36.6 & 7.5 \\
\hline
\end{tabular}


While the nitrogen content (NC) of the VF used for manufacturing the B50 was negligible $(\leq 0.1 \%)$, the NC of the recovered fibres was as high as $2.8 \%, 1.7 \%$ and $3.3 \%$ for RF1, RF2 and RF3, respectively (see Table 4). Thus, the resulting calculated binder content was $5.4 \%$ and $10.6 \%$ for RF2 and RF3, respectively (Table 4). Calculations were made on the amounts of initial binder contents found on the RF2 and RF3. The results revealed that the fibreboards possessed a relatively high tendency to be hydrolyzed. Furthermore, $46.6 \%, 47.0 \%$ and $66.2 \%$ of the initial binder content could still be found on the RF1, RF2 and RF3, respectively, implying that roughly half of the initial binder content was hydrolyzed and dissolved in the DW samples while an insignificant amount evaporated during the processes of disintegration and drainage or even both. Due to the complexity in the formulation, the proportions of the UF and MUF for RF1 cannot be calculated using the nitrogen content alone (Table 4).

Formaldehyde emissions of the VF after $3 \mathrm{~h}$ were 5.6 and $9.1 \mathrm{mg}$ per $\mathrm{kg}$ of the oven-dried (o.d.) fibres for the non-milled and hammer-milled samples, respectively (Table 4). As explained above, for NC, due to the remaining binder on the RF samples, formaldehyde emissions of the RF were 4.2 times higher than that of VF, on average. Thus, RF3, which contains higher amounts of NC (3.3\%), releases higher formaldehyde (36.6 mg per kg o.d. fibre) compared to the RF2 (29.6 mg per kg o.d. fibre). The formaldehyde release was not found to be proportional to the NC content. Thus, RF1 exhibited a slightly lower NC (2.8\%) compared to RF3 but released more amounts of formaldehyde (57.2 mg per kg o.d. fibre), although the binder contained MUF resin which is considered to be more stable during hydrolysis.

\subsection{Chemical Properties of the Disintegration Water (DW)}

The thermo-hydrolytic disintegration water samples obtained from the MDF panels exhibited higher $\mathrm{pH}$ values when compared to demineralized water (Table 5). This is attributed to the formation of ammonia $\left(\mathrm{NH}_{3}\right)$, which reacts with water to form ammonium hydroxide $\left(\mathrm{NH}_{4} \mathrm{OH}\right)$ [18]. The amount of formaldehyde present in the DW after the disintegration processes was $1618.8 \mathrm{mg} / \mathrm{L}$, $813.6 \mathrm{mg} / \mathrm{L}$, and $1385.3 \mathrm{mg} / \mathrm{L}$ for DW1, DW2 and DW3, respectively. Significant levels of reducing sugar equivalents are detected in the DW samples (shown in Table 5), which may be products having a cleavage, mainly consisting of hemicelluloses released during the production of VF and/or the thermo-hydrolysis of the MDF panels. The nitrogen content of the DW1, DW2 and DW3 was found to be $0.8 \%, 1.0 \%$ and $1.2 \%$, respectively (Table 5 ). On comparing the chemical properties of the DW samples to that of a previous study made by the authors [4], the screw press process was seen to have an alteration; the $\mathrm{pH}$ values were more alkaline, while the DW contained more dissolved UF (higher NC of the samples). Thus, higher formaldehyde content and fewer equivalents for reducing sugars were seen. A possible explanation for this alteration could be due to typically volatile ammonia, a by-product of the UF-resin breakdown, that would have been captured and not released, as the obtained recovered fibres together with the disintegration water were stored in barrels made of high-density polyethene and were sent to Maschinenfabrik Reinartz GmbH \& Co. KG (Neuss, Germany). 
Table 5 Chemical properties of the disintegration water (DW) obtained after the thermohydrolytic disintegration processes compared to the demineralized water mean values (MV) \pm standard deviation (SD).

\begin{tabular}{lllllllll}
\hline Chemical properties & DW1 & & DW2 & & DW3 & \multicolumn{2}{c}{$\begin{array}{l}\text { Demineralized } \\
\text { water }\end{array}$} \\
\hline & MV & SD & MV & SD & MV & SD & \\
pH & 5.7 & $\leq 0.1$ & 5.4 & $\leq 0.1$ & 6.4 & $\leq 0.1$ & 5.2 \\
$\begin{array}{l}\text { Formaldehyde content (mg L- } \\
\text { 1) }\end{array}$ & 1618.8 & 0.4 & 813.6 & $\leq 0.1$ & 1385.3 & $\leq 0.1$ & n.a. \\
$\begin{array}{l}\text { Reducing sugars } \\
\text { equivalents (mg L-1) }\end{array}$ & & & & & & & & \\
$\begin{array}{l}\text { Nitrogen content (\%) } \\
\text { Calculated UF content (\%) }\end{array}$ & 0.7 & 1.3 & 1.2 & 0.2 & 7.8 & 0.3 & 0.2 \\
\hline
\end{tabular}

\subsection{Physico-Mechanical and Chemical Properties of the MDF Panels}

It was seen that when $100 \%$ of the recovered fibres containing recycled MDF (B100) exhibited a slightly higher density, the B50 exhibited a lower density when compared to the target density (see Table 3). The recycled MDF containing $100 \%$ RF (B100) had an IB, which was nearly half as high as that of the original MDF (Board-2). The IB of the other recycled MDF (B50) was $28.5 \%$ lower than the original MDF, even though its final density was lower by $7.8 \%$. These results are contrary to the previous studies made by the authors [4], in which increased IB results were seen when $100 \%$ of the RF was used for the production of the recycled MDF. In addition, in the present study, the amount of binder content remaining on the RF was roughly $20 \%$ higher than the study mentioned above, and the fibres were severely shortened. Thus, the reduced IB of the B100 panel could be due to the over proportional consumption of the adhesive by fines and loss of strength of the RF [19]. The flexural strength (MOR) of the recycled MDF, B100 and B50 was lower by $59.8 \%$ and $21.5 \%$ than the original MDF panel, respectively. Similarly, the modulus of elasticity (MOE) of the recycled MDF panels was also reduced by the same range as the MOR compared to the original MDF. As for the IB, it can be attributed to the shortened fibre length due to the thermo-hydrolytic disintegration conditions, by subsequent hammer-milling and through the severe drainage process in the screw press. The properties related to the strength of these recycled MDF were significantly lower compared to those of the previous studies, which used the de-watering of the RF within a spin dryer [4]. In the MDF, the length of the fibre particularly determines the flexural strength and stiffness of the boards $[20,21]$. This indicates that a severe shortening of the RF occurs in the screw press. Another possible explanation for these reductions might be that the flexibility of the RF was reduced due to the thermo-hydrolytic disintegration process, making the RF more brittle. Brittleness, in turn, could lead to the shortening of fibre under the mechanical impact.

Compared to the original MDF panel (Board-2), the recycled MDF containing 50\% of RF displayed an $11 \%$ decrease in the thickness swelling (TS), while the other recycled MDF (B100) showed no difference. The latter result is surprising since the IB of the B100 variant was reduced by about $50 \%$, and the TS generally decreases with the increase in the bond quality. Water uptake (WU) after $24 \mathrm{~h}$ immersion, however, was increased with the average ca, two times for the recycled panels. When 
compared to two recycled panels, the slightly lower WU of B100 can be attributed to the reduced wettability of the RF due to the presence of the remaining resin. In addition, hydrophilic sugars derived from the degradation of hemicelluloses might be washed out during recycling. These sugars might absorb water, particularly in the virgin boards. Thus, the NC and the calculated UF content of the B100 was higher. B100 is supposed to contain ca. Nitrogen content of 3\% derived from the utilized $10 \%$ UF binder and $1.7 \%$ nitrogen is derived from the used RF. The obtained result of $4.9 \%$ NC is under this assumption, and the same applies accordingly to B50.

The formaldehyde content ( $2.0 \mathrm{mg}$ per $100 \mathrm{~g}$ o.d. board) of the original MDF panel was far below the upper limit value of $8 \mathrm{mg}$ per $100 \mathrm{~g}$ o.d. board, as per the standard EN 120 [7]. The recycled MDF, however, exhibited a very high amount of formaldehyde, which might have been derived from both the new UF resins that were used for producing the recycled MDF and the remaining binder on the RF.

Similarly, formaldehyde emissions of the recycled MDF panels were significantly higher than of the original MDF panels irrespective of the employed method (gas analyzer and flask). No difference was noted between the two recycled MDF panel types. In a previous study made by the authors [4], lower formaldehyde emissions were noted from the recycled boards compared to the virgin panels, which was attributed to scavenging of the formaldehyde due to reaction with urea, ammonia, and oligomeric decay products of the UF resin. This would result in lower formaldehyde emissions for B100 compared to B50.

However, it should also be noted that the limitations of the laboratory-scale production of the recycled MDF panels could cause some inconsistent physicomechanical and chemical results when compared to the industrially produced Board-2.

\section{Conclusions}

The present study aims to implement a drainage process based on the application of a screw press, which occurs in between the thermo-hydrolytic disintegration process and the further utilization of the obtained RF (e.g., for production of new panels). Compared to the previous study, which applied de-watering in a spin dryer, the screw press process produces dryer fibres but affects the chemical properties of RF as well as the DW differently. One of the most significant findings of this study is that the recycled MDF panels showed a decrease in mechanical properties compared to the original MDF panels. Although improvement in these properties was seen with the mixing of $\mathrm{RF}$ with VF, the strength of the panels containing only the VF were not received. Altogether, drainage in a screw press is very efficient; however, pressing too hard to achieve a low moisture content would result in severe fibre damage. Thus, either the pressing force must be reduced, or the RF should be used in combination with the VF to obtain better mechanical properties for the recycled MDF panels.

\section{Author Contributions}

F. Yağmur Bütün Buschalsky prepared the experimental design together with Carsten Mai. She performed the data collection, analysis and interpretation. Furthermore, she wrote the manuscript. Carsten Mai prepared the experimental design together with F. Yağmur Bütün Buschalsky. He assisted in data interpretation and manuscript writing. 


\section{Funding}

The authors wish to acknowledge funding by the AiF Project GmbH (project No. 16KN065229).

\section{Competing Interests}

The authors have declared that no competing interests exit.

\section{References}

1. FAO. Global forest products facts and figures 2018 [Internet]. Rome: FAO - Food and Agriculture Organization of the United Nations; 2019. Available from: http://www.fao.org/3/ca7415en/ca7415en.pdf.

2. Kharazipour A, Kües U. Recycling of wood composites and solid wood products. In: Wood production, wood technology, and biotechnological impacts. Göttingen: Universitätsverlag Göttingen; 2007. p. 509-533.

3. Bratkovich S, Bowyer J, Lindburg A, Fernholz K. Reclaiming lumber products from waste wood. Minneapolis, MN, U.S.: Dovetail Partners, Inc; 2009.

4. Bütün Buschalsky FY, Mai C. Repeated thermo-hydrolytic disintegration of medium density fbreboards (MDF) for the production of new MDF. Eur J Wood Wood Prod. 2021. doi: 10.1007/s00107-021-01739-6.

5. Bütün FY, Sauerbier P, Militz H, Mai C. The effect of fibreboard (MDF) disintegration technique on wood polymer composites (WPC) produced with recovered wood particles. Compos Part A Appl Sci Manuf. 2019; 118: 312-316.

6. EN 717-3. Wood-based panels - Determination of formaldehyde release Part3: Formaldehyde release by the flask method. 1996. Available from: https://standards.iteh.ai/catalog/standards/cen/d5780cf9-a83b-427a-b791-a8f0afd64ff4/en717-3-1996.

7. EN 120. Wood-based panels - Determination of foemaldehyde content; extraction method called the perforator method. 1992. Available from: https://standards.iteh.ai/catalog/standards/cen/afc725fb-e800-436b-ae2b-1f02a5bc8120/en120-1992.

8. Miller GL. Use of dinitrosalicylic acid reagent for determination of reducing sugar. Anal Chem. 1959; 31: 426-428.

9. EN 323. Wood-based panels -Determination of density. 1993. Available from: https://standards.iteh.ai/catalog/standards/cen/80828f22-b8f1-4d4c-935a-b4ffbf97e905/en323-1993.

10. EN 322. Wood-based panels - Determination of moisture content. 1993. Available from: https://standards.iteh.ai/catalog/standards/cen/8d40667c-5f05-47be-a516dd61270654ca/en-322-1993.

11. EN 319. Particleboards and fibreboards - Determination of tensile strength perpendicular to the plane of the board. 1993. Available from: https://standards.iteh.ai/catalog/standards/cen/476c6e54-1b1a-491d-90a993da4e3601a5/en-319-1993. 
12. EN 317. Particleboards and fibreboards - Determination of swelling in thickness after immersion in water. 1993. Available from: https://standards.iteh.ai/catalog/standards/cen/fc56d369a9c5-489f-a1cb-115e7082aa5b/en-317-1993.

13. EN 310. Wood-based panels - Determination of modulus of elasticity in bending and of bending strength. 1993. Available from: https://standards.iteh.ai/catalog/standards/cen/Obc47eac778e-4f85-8f99-9d0b9fc36dc8/en-310-1993.

14. EN 717-2. Wood-based panels - Determination of formaldehyde release Part2: Formaldehyde release by the gas analysis method. 1995. Available from:

https://standards.iteh.ai/catalog/standards/cen/d1cceafb-d226-4529-a12c8eb819d1a62d/en-717-2-1994.

15. Glass SV, Zelinka SL. Moisture relations and physical properties of wood. In: Wood handbook: Wood as an engineering material: Chapter 4. Madison, WI, U.S.: Dept. of Agriculture, Forest Service, Forest Products Laboratory; 2010.

16. Roffael E, Hüster H-G. Complex chemical interactions on thermo hydrolytic degradation of urea formaldehyde resins (UF-resins) in recycling UF-bonded boards. Eur J Wood Wood Prod. 2012; 70: 401-405.

17. Wan H, Wang X-M, Barry A, Shen J. Recycling wood composite panels: Characterizing recycled materials. BioResources. 2014; 9: 7554-7565.

18. Moezzipour B, Ahmadi M, Abdolkhani A, Doosthoseini K. Chemical changes of wood fibers after hydrothermal recycling of MDF wastes. J Indian Acad Wood Sci. 2017; 14: 133-138.

19. Roffael E, Behn C, Schneider T, Krug D. Bonding of recycled fibres with urea-formaldehyde resins. Int Wood Prod J. 2016; 7: 36-45.

20. Steffen A, Janssen A, Kruse K. Analysis of the MDF production process by means of statistical process modelling. Eur J Wood Wood Prod. 2001; 58: 419-431.

21. Benthien JT, Bähnisch C, Heldner S, Ohlmeyer M. Effect of fiber size distribution on mediumdensity fiberboard properties caused by varied steaming time and temperature of defibration process. Wood Fiber Sci. 2014; 46: 175-185.

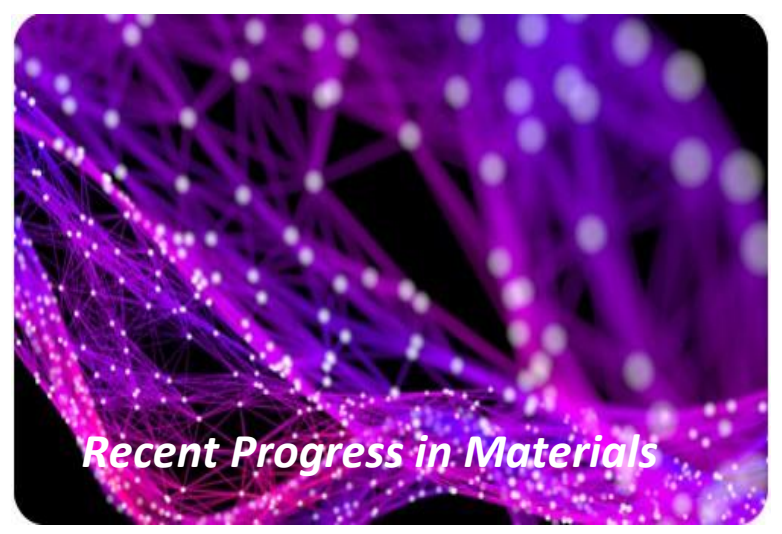

Enjoy Recent Progress in Materials by:

1. Submitting a manuscript

2. Joining in volunteer reviewer bank

3. Joining Editorial Board

4. Guest editing a special issue

For more details, please visit:

http://www.lidsen.com/journals/rpm 